\title{
La institución del teatro, institución del Estado
}

Katherine Miller

Directora de Asuntos Culturales Biblioteca "Florentino Idoate, S. J." Universidad Centroamericana"José Simeón Cañas"

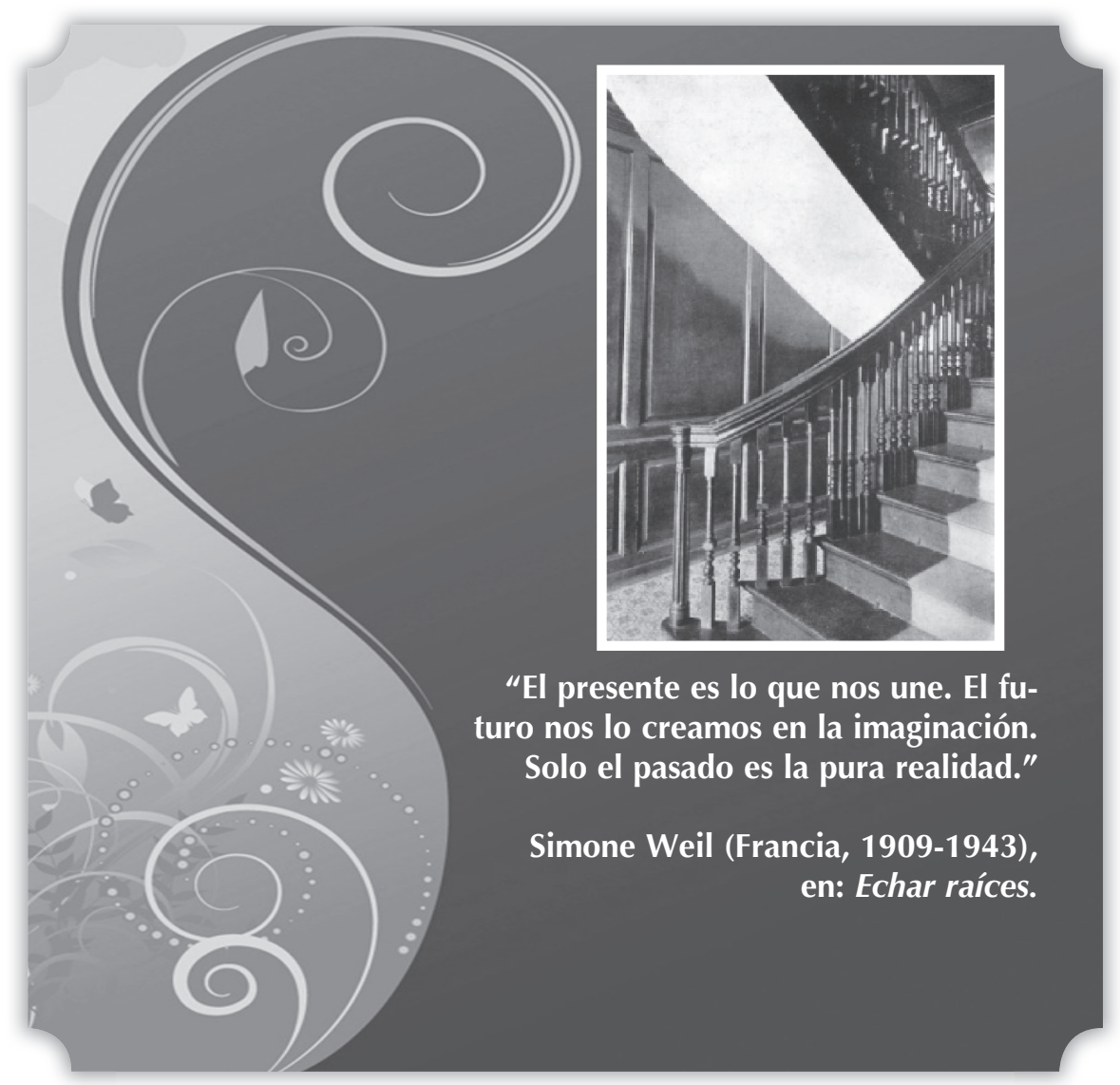




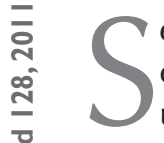
e ha dicho que, si se desea conocer algo sobre la salud de una nación, no hay mejor manera que examinar su teatro; porque este refleja su salud social y política. Las audiencias de cada Gran Festival de Dionisio en la Antigua Grecia Ilegaron a unos 30,000 hombres. En la Inglaterra del Renacimiento, un estudio de los libros de contaduría de las compañías de actores, y otra documentación, señala una asistencia de aproximadamente 25,000 personas de ambos sexos y todas las clases sociales del país cada semana, Ilegando a mas de 50 millones de espectadores para los períodos Tudor y Estuardo, cuando Londres tenía una población que oscilaba entre 180,000 y 200,000 personas.

Así que nos ocuparemos en este ensayo de la energía social y el otorgamiento de poder que surgen, intencionalmente, de lo que mantengo que es una de las instituciones del estado: el teatro. Es decir, la tesis a proponer, y defender, es que la institución del teatro participa en el desarrollo de un estado. La institución del teatro funciona en una combinación con las necesidades del estado que sirve. Además, como válvula de control y transmisión de energías sociales y otorgamientos de poderes que intencionalmente son suscitados por el teatro en la audiencia, después dirige estas energías en tal manera que no estorban el funcionamiento del estado según el régimen gubernamental del momento. Es posible, también, se- gún los ejemplos que presentaremos aquí, que el teatro pueda apoyar activamente y presentar correctivos y proponer objetivos para el estado en su manifestación de turno.

Después de las efusiones pasionales del romanticismo durante los siglos XVIII y XIX, la visión tradicional del arte como producción cultural que glorifica el individuo y sus luchas contra el estado $-y$ aquí se incluye el arte dramático del teatro- se ha cimentado una visión del papel del arte y del teatro que corresponde a las visiones revolucionarios del siglo XIX, y aun en el siglo XXI sigue en vigencia esta visión. El arte, según esta apreciación, es subversivo, y busca la libertad del individuo $y$, por lo tanto, hay que admirar este espectáculo cultural del teatro como instrumento que anima la primacía de actos que glorifican el individuo en todo su esplendido aislamiento político.

La ironía, en esta percepción del espectáculo teatral, este "suspiro de libertad" del artista y audiencia, es que si no se quitan los lentes ideológicos para penetrar el superficie del espectáculo (teatro, televisión, eventos mediáticos), no se puede interpretar las verdaderas relaciones de poder en el arte dramático y el espectáculo. Si insistimos en ver el teatro como una expresión de una mariposa libre sin ataduras a las fuerzas políticas para la educación de la ciudadanía, nos estamos engañándonos. 
Pero desde sus orígenes, pasando por el desarrollo histórico de este fenómeno, el teatro, enfrenta otra dialéctica, si lo examinamos en el contexto político del estado en que funciona, comenzando, por supuesto, con los griegos.

Primero, siempre, viene Platón y su desprecio de la poesía (léase, tragedia dramática, además de Homero) en su República, por razones éticas y filosóficas. Platón ha sido denominado, por historiadores recientes, como "el primer policía del pensamiento político" (Goldhill, Cambridge, 1990). El teatro no era filosofía para Platón; el arte dramática de los poetas no era argumentación sistemática ni actividad de pensamiento rigorosa. Por estas razones, el teatro, declara Platón, no puede ser utilizado para enseñar; solamente la argumentación rigurosa de la filosofía--aunque su estudiante, Aristóteles, intentó salvarlo como experiencia pedagógico para la audiencia.

Sin embargo, se ha notado que el teatro, siendo un lugar donde "hablan" y "miran" [theatron, lugar de ver y mirar], es análogo a las cortes de leyes y la asamblea (boulé) de los griegos del siglo $\mathrm{V}$ a. de C., donde también "hablan" y toman decisiones para la ciudadanía, compuesta por los hombres adultos de Atenas que cumplen con ciertas características.

El argumento que se propone en este ensayo, sin embargo, es que el teatro forma una parte fundamental, históricamente —si no filosóficamente- como factor fundamental en la politicización de la ciudadanía de Atenas, quienes, veremos, fueron obligados como deber cívico, asistir al Gran Festival de Dionisio. Y el estado obligó algunos de los más ricos, financiar el teatro y los dramaturgos, por medio de una red de instituciones para "formar" la relación de la ciudadanía con el estado.

Consideramos lo siguiente. El Gran Festival de Dionisio (The Great Dionisia) consistió en cuatro ceremonias presentadas en el teatro frente a los ciudadanos de Atenas, antes de que comenzaran las obras dramáticas. Estas ceremonias expresaron ideales cívicas y comenzaron con una presentación de los diez estrategos (generales militares activos) en un conjunto con las figuras políticas y militares pre-eminentes del estado, quienes vertieron una libación ritual para el sacrificio a los dioses. Era con esta ceremonia de militares que suplicaban a los dioses de parte del estado de Atenas, que comenzó este festival teatral enormemente importante para la educación e integración de la ciudadanía al estado (polis). Este acto subrayó, podemos decir, el carácter político del festival dramático.

Enseguida, un heraldo (oficial del estado) anunció a la audiencia, los nombres de los ciudadanos que habían hecho donaciones a beneficio del estado y quienes, por eso, 
habían recibido una corona para sus servicios. He aquí el deber, la obligación, del individuo a servir y contribuir al estado. Estas personas fueron elogiadas oficialmente frente a la audiencia de ciudadanos y diplomáticos, obligados a asistir.

Una procesión conformó la tercera ceremonia que ostentaba toda el oro y la plata pagado por todos los estados del imperio de Atenas (originalmente, la Liga de Delos) como tributo obligatorio al imperio de Atenas, presentando así una Iluvia de gloria a Atenas como poder político y militar. (Y era precisamente para presenciar sus tributos en exhibición que los embajadores extranjeros en Atenas fueron requeridos asistir el teatro.)

Finalmente, en una cuarta ceremonia antes de que comenzaran las obras dramáticas programadas para el Gran Festival en honor de Dionisio, los ephebes desfilaron ante el público allí presente. Los ephebes eran los huérfanos de guerra criados y educados al costo del estado porque sus padres habían caídos en batalla en las guerras de Atenas. Cuando alcanzaron la edad de ser hombres, fueron presentados en el teatro en vestuario militar ceremonial (provisto también por el estado) y tomaron un juramento público prometiendo luchar y morir por el estado así como habían hecho sus padres. En esta manera, la obligación militar del ciudadano hacia el estado se exhibía metafóricamente.

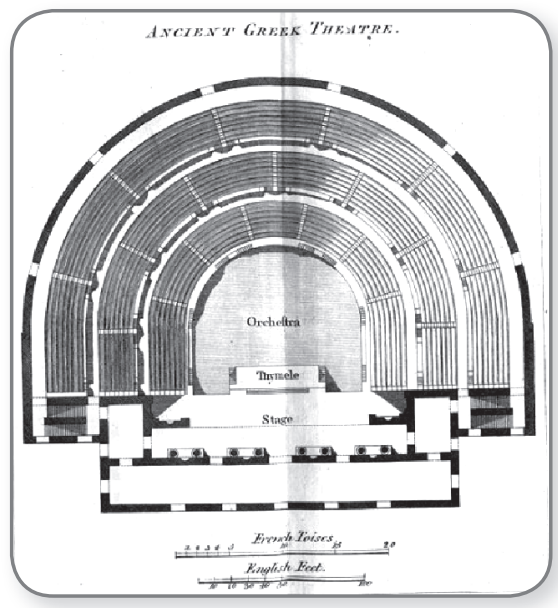

Solamente después de estas ceremonias pudieran comenzar las actividades dramáticas del Gran Festival de Dionisio. Entonces, los festivales dramáticos fueron diseñados para comenzar con ceremonias políticos y militares con el objetivo de (1) proyectar la gloria y poder de Atenas y (2) para formalizar, públicamente, la ideología de la participación del ciudadano en el estado.

Los dramaturgos fueron escogidos por el arconte epónimo [Eponymous Archon] y recibieron estipendios del estado para escribir sus obras. El financiamiento de las producciones (los actores y el coro) fue la responsabilidad de los pentakosiomedimnoi [ciudadanos de Atenas que produjeron un mínimo de 500 medidas - the five-hundred measure men - quienes pagaron una "liturgia" [liturgy], una especie de impuesto obligatorio, para financiar o la producción teatral, o para financiar la construcción de un 
trirreme [barco de la flota militar de Atenas], u otro proyecto del estado con sus ganancias enormes.

Los que formaron el jurado para decidir los ganadores de los premios por obras dramáticas fueron escogidos de entre los representantes de los tribus de Atenas. La actividad del gran festival de Dionisio y los fondos para su implementación fueron sujetos a una revisión contable por una asamblea especial gubernamental para asegurar la transparencia de los principios financieros de esta institución tan importante al estado.

Obviamente, el teatro formó parte del control e integración, inclusión social del estado hacia sus ciudadanos. Los esquemas y arreglos de quien deberá sentarse donde, etc. son muy específicos, los cuales, en el interés de brevedad, omitimos aquí. El asunto es el carácter educativo y obligatorio, además de los aspectos estéticos de la poesía con que re-escribieron estos episodios míticos con el objetivo de purgar y purificar la audiencia de las peligrosas, pero atrayentes ideas de un compromiso consigo mismo encima de un compromiso con el estado (comunidad, polis, etc.).

Falta una discusión del contenido de algunas obras representativas para ver el propósito político de las obras mismas presentadas en este gran festival. Lo más obvio es la Orestiada de Esquilo, en que vea- mos el movimiento y proceso desde la venganza personal o familial de la casa de Atreo, pasando por el control social de la violencia y llegando, en su conclusión, a la incorporación y educación del ciudadano a la ciudadanía en formación de la corte legal (areópago) instituido por la misma Palas Atenea, en que los ciudadanos tomaron parte como jurado, y así fueron incluidos en el estado para escuchar argumentos a favor y en contra en el enjuiciamiento de Orestes por haber matado a su madre para vengar a su padre. La función social de incorporación política de los ciudadanos en la institución judicial de la corte del areópago es clara.

La institución del teatro en su producción pública y cívico, de tragedias en la Atenas, en que el teatro representa el espectáculo, financiado por el estado, juzgado para la adjudicación de premios por parte de jurados seleccionados por el estado y fue, finalmente, supervisada contablemente por el estado.

"It was an enormous civic event; a purposeful political act of community [....] These plays were made for performance as part of the political life of the city." [Fue un evento cívico enorme; un acto político con objetivo, un acto político de la comunidad. [....] Estas obras fueron producidas como parte de la vida política de la ciudad.] (The Oxford Illustrated History of the Theatre. John Russell Brown, 
ed. Oxford University Press, 1997. Traducción propia)

Estas obras dramáticas teníanfunciones políticas que no estaban separadas del estado ni del gobierno: sirvieron a sus fines, $y$, por eso fueron financiados por el Boulé (asamblea gubernamental del estado), que, también distribuyó boletos de entrada sin costo a los representantes de las tribus de Grecia para asegurar su asistencia al teatro.

Es que, el teatro (ya sea tragedia o comedia) en la Grecia Antigua, era un instrumento para ventilar posibles desviaciones y críticas en las estructuras de pensamiento en riesgo y sujetarlos al escrutinio en la arena pública de un festival cívico para así involucrar a la ciudadanía y líderes políticos de Atenas en una participación sana, limpiada por medio de la catarsis, del ideal de la participación de ciudadano en el estado en forma aceptable y correcta. En esta manera, se puede examinar públicamente, fenómenos de trasgresión versus el orden estatal y el posible compromiso - tan peligroso y atractivo que esde elevar sentimientos individuales o familia encima del compromiso con el estado.

Los espectáculos teatrales públicos, entonces, sirven para mucho más que para ofrecer "pan y circo", o para aplacar tendencias insurreccionales $u$ otras actividades o pensamientos desviados. En este argumento, omito el ejemplo obvio que contradice, ostensiblemente, este tesis: el Prometeo de Esquilo, quien es castigado por Zeus por haber robado el fuego de los dioses para regalarlo a los humanos. Los críticos románticos (visión del siglo XVIII-XIX, aunque promulgado en el siglo XXI todavía) elogian esta tragedia como el grito de insurrección contra los dioses, insinuando que son injustos y hay que enfrentarse contra ellos. Esta obra termina con el grito del titán Prometeo: "Sufro injustamente".

¿Por qué lo omito? Porque es la primera obra en una trilogía, género que desarrolla, premisa por premisa, en sus tres partes, un tema desde unas acciones equivocadas o incompletas, culminando en una tercera obra que presenta las formulaciones finales de la trilogía, así como La orestiada de Equilo, que veremos abajo. La orestiada presenta y desarrolla el tema de la justicia en la vida de Grecia. La orestiada plantea, en la primera obra, el Agamenón, el problema, para principiar, de la venganza de sangre como única oportunidad para resolver la situación presentada. Pero no deja la problemática en lo que está planteado solamente en la primera obra de esta trilogía, que sobrevive en su totalidad.

Como sabemos, la progresión de la problemática de justicia termina con la implementación de una corte de justicia con defensor, fiscal y jurado: el areópago. Si la presen- 
tación de la problemática, entonces, había quedado solamente con el Agamenón, los actos de Orestes, et al., en el contexto no de la familia ni por actos individuales sino que dentro del contexto de una institución del estado. Y, así, la venganza individual de sangre dentro de la familia sería la formulación de lo que quería declarar Esquilo: lejos de quedar con la venganza familial, presentada en el Agamenón, Esquilo propone la justicia de una corte del estado, una institución judicial, que sería necesaria para resolver pleitos como los presentados inicialmente entre Clytemnestra y Agamenón.

El Prometeo, de otro modo es solamente la primera parte $-y$ la única que sobrevive de la trilogía que escribió Esquilo. Es el único que tenemos y así es solamente la primera premisa, o, planteamiento de la problemática de la relación del individuo con el estado y los dioses. Es incompleto y no presenta el "desenvolvimiento", desenlace, final que propone Esquilo, porque no sobrevive la segunda y tercera parte de esta trilogía. Quedamos cortos y no podemos tragar como la propuesta final de Esquilo, solamente el Prometeo, con la crítica azucarada de la visión revolucionaria decimonónica.

Sería provechoso examinar bajo la lupa de la visión propuesta —es decir, que el teatro es, y funciona como, una institución del estado y por los intereses del estado- la obra Antígona de Sófocles. Esta obra se presta a un examen del pensamiento en riesgo y las posibles desviaciones políticas de individuos en el estado.

Siglos de profesores de colegios y universidades han proporcionado a sus alumnos la cucharada del individuo moralmente comprometido en conflicto contra un estado injusto -los intereses del individuo y la familia contra el estado. Así, la Antígona de Sófocles ha sido presentada como la tragedia y la gloria de la lucha individual contra la injusticia moral del estado. Jean Anouilh, en el siglo XX, hasta la produjo como metáfora de la resistencia contra la ocupación nazi de Francia durante la Segunda Guerra Mundial.

Se propone comparar estas interpretaciones con un análisis que habría hecho una audiencia griega contemporánea de esta obra en el Gran Festival de Dionisio en el siglo $\checkmark$ a. de C.

Pero deseo presentar una intromisión para nuestra consideración, antes de seguir. En las interpretaciones ofrecidas aquí, casi todo depende de nuestra concepción del estado. Si en lugar de ver el estado como un aparato opresor contra que el individuo tiene que luchar (visión romántica del siglo XIX), los vemos como la infraestructura sobre la que se confecciona una nación, podemos apreciar los esfuerzos de los dramaturgos griegos del siglo $\mathrm{V}$ 
a. de C. al servicio del estado para aportar a esta construcción cultural, la nación y el estado. La apreciación de las obras dramáticas de la antigüedad, el imperio romano, la antigüedad tardía, o la Inglaterra jacobina requiere unos cambios de velocidad y vueltas del timón para aproximarnos al contexto y ajustar nuestra visión, en la medida posible, para acercarnos a la obra en la manera y en el contexto que tenía la audiencia para quienes estaban escritas y producidas en el escenario públicamente: es decir, en conflación con las necesidades del estado o nación en proceso de construcción.

Pero antes, se tienen que esparcir los vientos críticos, no solamente de las teorías críticas surgidas del siglo XIX, sino también, de los del formalismo (The New Criticism) del siglo XX, para intentar eliminar las distorsiones que imponen lecturas modernas, pero tradicionales y de costumbre continuo y sin contexto, de estas obras antiguas.

Las visiones críticas practicados en la sombra del romanticismo - o Romanticismo- insisten en diagnosticar análisis que enfatizan la brillantez de los héroes en su lucha solitaria contra las fuerzas del estado o gobierno, que, por criterios propios del siglo XIX, son injustos. Estas tendencias de interpretación elogian las simpatías siempre con el individuo revolucionario. Esta es una distorsión porque nos lleva im- poner visiones de 500 años después de la obra y así obstaculizar un entendimiento de que la audiencia original de ciudadanos de Atenas iba a recibir como parte de su educación político para su inclusión en el estado (polis). Es decir, para los ciudadanos griegos presenciando el Gran Festival de Dionisio, Antígona no es la heroína ni la figura trágica. Ya veremos por qué, más adelante.) Pero, por ahora, no es que esté cayendo en la duplicidad de asignar las intenciones del autor como la clave del entendimiento. Lejos de eso. Deseo enfatizar la función de esta obra, en el teatro como institución del estado, financiada por el estado, que proyecta un problemática para la consideración de la audiencia de hombres, ciudadanos del estado (polis) de Atenas.

$\mathrm{Y}$, por el momento, seguimos con el segundo par de lentes que distorsionan: son los del formalismo, en inglés de las universidades angloamericanos. Esta es The New Criticism, una escuela del pensamiento crítico literario que comenzó en Europa Occidental y EE.UU. durante la década de los 50 durante la Guerra Fría, y que penetró hasta la crítica literaria de los tiempos. En el afán occidental de enfrentar y superar al éxito del Sputnik, los angloamericanos optaron por un prejuicio a favor de la ciencia y desbarataron los análisis de tinte humanístico. El Ilamado New Criticism del siglo XX divorció el "objeto literario" de todos sus contextos 
históricos de cualquier índole y la diseccionaron con el escalpelo de ingenio abstracto y científico, que redujo la obra literario a un "ítem" sujeto a análisis abstractos. (Véase C. P. Snow, Las dos culturas y R. P. Blackmur, The Lion and the Honeycomb.)

En esta visión en que la obra se vuelve "objeto", o globo de cristal suspendido en el aire, sin ligamentos a la sociedad ni la historia del pensamiento intelectual o político, Antígona se vuelve una heroína abstracta, una mujer que lucha contra los esfuerzos de una sociedad masculina y autoritaria, absurda y sin sentido. (Léase la Mujer Maravilla agente de la CIA, contra la sociedad gris y opresiva de la URSS con su KGB).

Para no apuñalar ballenas en un barril, ni azotar un caballo muerto, permítan decir, entonces, que la audiencia de la obra Antígona, el drama trágico e decisiones morales y confrontación de los compromisos y obligaciones con el estado, fue presentado en el Gran Festival de Dionisio en el año 442 a. de C. ante una audiencia de los ciudadanos masculinos de Atenas. Antígona es la última obra de la trilogía de Tebas, que se desglose en el siguiente orden: Edipo Rey, Edipo en Colona y, finalmente, Antígona. Los actores también eran todos hombres que utilizaron máscaras para que no pudieran ver sus caras, ni sus expresiones emocionales. $\mathrm{Y}$ utilizaron vestuario teatral de gran tamaño, pesado y tieso. No había ninguna Irene Papas ni Genievieve Bujold para fascinar a la audiencia con sus ojos penetrantes y bellas pasiones y gestos modernos. Era un asunto completamente masculino. Solamente la voz proyectada a través de la máscara delineaba el accionar, los pensamientos y los debates morales de la tragedia.

El debate presentado en la obra, para no alargar el asunto, consiste en un decreto emitido por el rey Creonte (nombre en griego, no personal, si no que genérico que significa, sencillamente, "líder" o "rey" de un estado). El decreto consiste en que el hermano de Ismene y Antígona, sobrinas de Creonte, de nombre Polínices, uno de los hijos de Edipo, es considerado por el estado de Tebas como traidor contra el estado
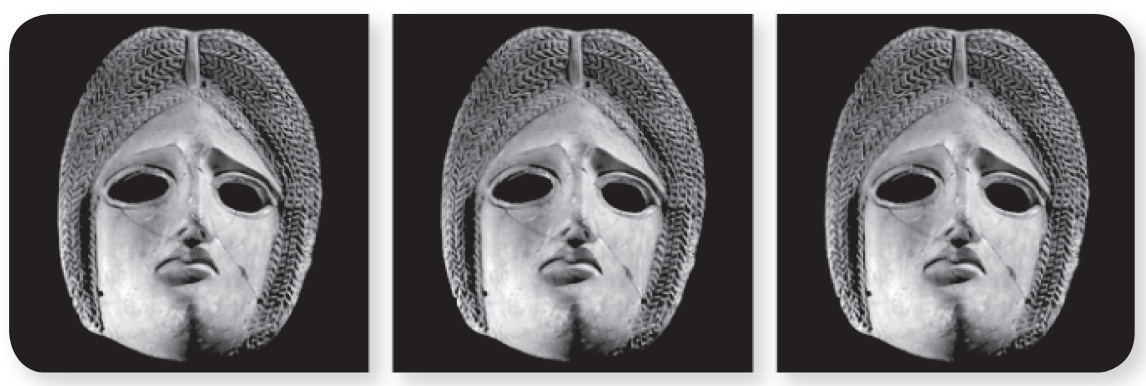
y es negado los ritos religiosos del entierro que los dioses obligan a los humanos a observar. Creonte, sin embargo, ha ordenado que nadie pueda celebrar estos ritos, porque Polínices es traidor contra el estado, que su cadáver deba quedar fuera de las murallas de la ciudad para que los perros y aves lo devoren. Esta es la ley humana del estado.

Unas palabras breves sobre Sófocles, el autor de esta tragedia, antes de seguir, para que no nos equivoquemos de su papel en el imperio de Atenas en la cima de su poder. No vayan a olvidar lo que nos dice Tucídides, escribiendo sobre la Guerra del Peloponeso (431 - 404 a. de C.): la Asamblea (Boulé, cuerpo gubernamental del estado (polis) democrático de Atenas) debatió en toda seriedad si Atenas deberá practicar genocidio contra las poblaciones de Mitilene durante la Guerra del Peloponeso, y enviaron barcos de militares para cumplir con esta tarea encomendado por el estado de Atenas. Cuando se habían ido los barcos, el día siguiente, cambiaron de decisión (otro voto) y enviaron barcos más veloces para dejar la decisión sin efecto. Solamente por suerte alcanzaron a los primeros barcos que llevaban el orden de eliminar físicamente la población de Mitilene durante la Guerra del Peloponeso reportado por Tucídides. La Asamblea, con toda frescura, debatió, también (Tucídides nos presenta sus discursos) si deberán hacer la misma cosa con la población de Melos. En el famoso diálogo sobre Melos, los atenienses decidieron, por voto de la Asamblea, cometer genocidio contra los de Melos y ejecutaron a todos los hombres y vendieron a todas las mujeres y a los niños al tráfico de esclavos. El estado democrático de Atenas, en la tragedia dramática que nos presenta Tucídides en su Historia de la guerra del Peloponeso, en un período de unos diez años antes de la primera producción de Antígona de Sófocles. Favor tomar nota que Atenas fue capaz de mantener su estado por medio de las medidas descritas por Tucídides.

Regresando a Sófocles, así como Tucídides, Esquilo y Eurípides, Sófocles era un estratego, general militar activo, además de un oficial del estado encomendado a ser encargado de todo el tributo de oro y plata entregado al imperio de Atenas. Asi que, podemos ver que el estado tenía mucha confianza en él, y, después de la desastrosa expedición a Sicilia votada por la Asamblea de Atenas, que nos cuenta Tucídides, Sófocles formó parte de la comisión para examinar el desenlace del desastre en Sicilia. Además, escribió tragedias, encomendado por el estado y producidos en el Gran Festival de Dionisio. Uno de estas es su Antígona. El punto es que Sófocles no era un rebelde contra el estado.

En la tragedia Antígona, Sófocles plantea el dilema: ¿Son incom- 
patibles las obligaciones familiares con las obligaciones que se debe al estado? Antígona toma una posición endurecida de que los costumbres y tradiciones de la familia, mas las obligaciones a los dioses tienen preeminencia sobre las leyes del estado.

Debemos tomar nota bien que en el momento cuando Antígona expresa esta decisión, el coro canta una oda (muy famosa) que elogia al hombre ("Oda al Hombre"), que termina con los siguientes sentimientos: Cuando las leyes son obedecidas, orgullo tendrá la ciudad; pero cuando las leyes no son respetadas, ¿qué pasará con la ciudad? Nunca, canta el coro, al final de esta oda, puede el hombre sin estado encontrar descanso cerca del fuego en mi hogar. $Y$ nunca sus pensamientos serán mis pensamientos, declama el coro precisamente en el momento en que Antígona se enfrenta contra las leyes de Creonte, del estado, y propone practicar los ritos para su hermano, en contra del decreto de Creonte prohibiéndolo.
Volteamos la vista otra vez a la situación de esta producción en Atenas donde solamente la voz proclama las líneas de la tragedia. La audiencia de hombres atenienses sentados en el teatro simpatizaban con Antígona porque su destino es injusto e inmerecido (es condenada a morir encerrada en una cueva por haber practicado los ritos religiosos para su hermano muerto, Polinices, prohibidos por el decreto estatal de Creonte por considerarlo como un traidor contra el estado). En alguna manera Antígona tiene razón, pensará la audiencia.

Pero, permítanme proponer que la figura trágica de esta obra no es Antígona. Es Creonte. Es Creonte, quien, por su intransigencia, ha perdido a su hijo, a su esposa y a su sobrina. Para los ciudadanos, todos hombres, de la Atenas de Pericles, la muerte de Antígona trae consigo la disolución de la familia de Creonte. Este queda como un hombre sin estado, en exilio. Creonte, y no Antígona, es la figura trágica para la audiencia de Atenas de Perícles.

\section{Transiciones desde Grecia a Inglaterra}

Viajemos, un momento, desde la Atenas del siglo $\mathrm{V}$ a. de $\mathrm{C}$., hacia las grandes tragedias isabelinas y jacobinas del Inglaterra de Shakespeare, y veremos la continuidad de los temas presentados, similares y alusivos a los de las tragedias griegas que se ha presentadas arriba, $y$ el funcionamiento del teatro como institución del estado en el siglo XVI —durante el Renacimiento de Europa Occidental.

Hemos notado la similitud entre el arte oratorio y retórico de los políticos en la asamblea igual como sus similitudes con el arte de declamar en las cortes judiciales. 
Brevemente, se debe notar, al pasar estos siglos, que el teatro en Roma no murió, si no que sobrevivió en una forma que era imitación del teatro griego. Richard C. Beacham, en su estudio del teatro romano y su función en el ámbito de las estrategias del estado romano de "pan y circo", Roman theatre and its audience (Harvard University Press, 1991), nota que:

"The art of oratory was nurtured and recognized to be of supreme significance throughout Roman history, not only for obtaining public office, but for exercising effective power both within the institutions of the Roman state, and in times of political crisis, outside of them as well. Later commentators-including a number of the most renowned orators-frequently compared its skills and reception to those of theatrical art."

[El arte oratorio era criado y reconocido como de significado supremo por toda la historia romana, no solamente para ganar un puesto público, si no para el ejercicio efectivo del poder dentro de las instituciones del estado romano, y en tiempos de crisis política, fuera de ellas. Los comentaristas que siguieron después, incluyendo varios oradores de renombre- con frecuencia compararon las habilidades y recepción [de la oratoria] a las del arte del teatro.] [Traducción propia. Las cursivas son mías).
Después del auge del Imperio Romano y durante el período que denominamos la Antigüedad Tardía y la Temprana Edad Media (Renacimientos) en Europa Occidental, el teatro y drama de los griegos fue poco conocido a causa de la división entre el Imperio de Roma Occidental y el Imperio Romano en Bizancio (Constantinopla), donde sí fueron muy conocidos.

Durante estos períodos de transición, se fragmentó el Imperio Romano en Occidente; las estructuras institucionales de administración del imperio decayeron y paulatinamente fueron remplazadas con las estructuras administrativas diocesanos de la Iglesia Occidental. Hasta 1453, con la caída de Constantinopla ante los turcos otomanos, podían llegar al Occidente (Ravena, etc.) y fueron conocidos, al fin de tanto, los manuscritos en griego de Platón, Aristóteles, Tucídides, Herodoto, Esquilo, Sófocles, Eurípides y todos los demás que enseguida fueron traducidos al latín y después, a las lenguas vernáculas románicas de italiano, inglés, francés, etc., por los humanistas cívicos.

Con la fragmentación administrativa y militar del Imperio Romano durante la Antigüedad Tardía, Europa no tenía ni un centro político ni cultural. Retoman esta función las diócesis de la Iglesia Latina con sus obispos que se encargaron no solamente de las necesidades religiosas 
de las poblaciones, si no que también funcionaban como gobierno civil al nivel local.

El control del estado sobre el teatro, que no era solamente cristiano y litúrgico, porque el teatro y procesiones romanos continuaban simultáneamente, pasó a las estructuras diocesanas de la Iglesia y tenemos las traducciones de la Abadesa Hroswitha von Gandersheim y Hildegard von Bingen (ambas del siglo IX), aprobadas, por supuesto, por su obispo, de las obras dramáticas de Terencio y Plauto y otras obras dramáticas, lavados y expurgados sus textos para que brillaran las virtudes de las vírgenes mártires, etc. La Iglesia (a nivel local, los obispos de las diócesis) tenía control perfecto del estado (así como el estado tenía control en Grecia Antigua) sobre estos vestigios del teatro, ya que fueron presentados en monasterios y atrios de las iglesias, después de sus traducciones por dramaturgas como Hildegaard von Bingen y Hroswitha von Gandersheim.

Cuatrocientos años más tarde, Ilegando a la gran época de tragedia es la época isabelina y jacobina (de la Reina Isabel I y su sucesor, el Rey Jacobo) cuando escribió Christopher Marlowe y WiIliam Shakespeare, entre otros.

¿Cuál es el vínculo entre la tragedia griega y la tragedia isabelina y jacobina, si es que lo hay? Y, por supuesto, lo hay.

Las fechas de Shakespeare son 1554-1616. Marlowe era su contemporáneo, junto con Ben Jonson y toda la tribu de dramaturgos londinenses. Estos hombres escribieron para el escenario de los comerciantes (incluyendo a Shakespeare)

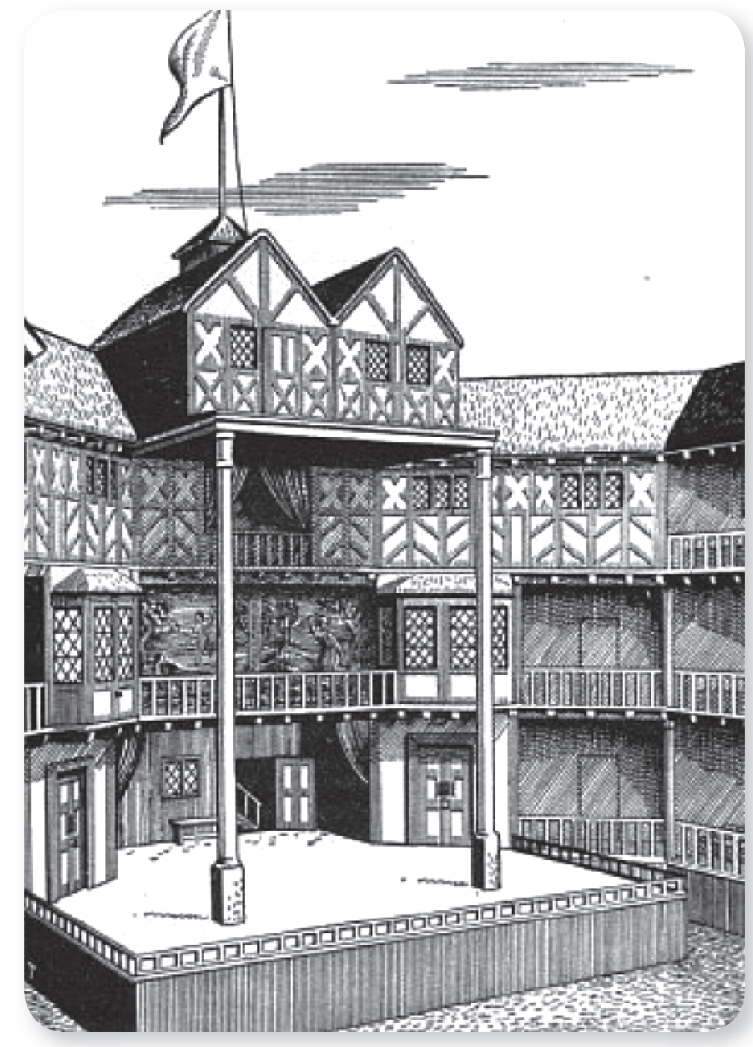


y para las compañías de actores como The Lord Chamberlain's Men, entre otros, quienes produjeron estas famosas tragedias en los teatros de Shoreditch, fuera de los límites municipales de Londres. ¿Acaso Marlowe, Shakespeare y demás conocieron a los griegos antiguos?

La historia de Antigua Grecia y la Cuenca del Mediterráneo Oriental escrito en el primer siglo a. de C. por Diodoro Siculo (Diodoro el Siciliano (un griego de Magna Grecia)) fue conocido en la Corte de Enrique VII, porque el sacerdote inglés, humanista y pedagogo del joven Enrique (mas tarde Enrique VIII), y también orator regius de la corte en Londres, John Skelton tradujo la Bibliotheca historica de Diodoro Siculo al inglés del última década durante siglo XV y fue publicada en Londres por la imprenta humanista de William Caxton. Así, la historia de la Magna Grecia estuvo disponible en el Londres de Shakespeare, Marlowe y demás.

En 1566, las partes principales de la trilogía de Esquilo, La orestia$d a$, fueron traducidas y publicadas en Londres por un tal John Studley, Fellow de Trinity College, Cambridge University. La orestiada, entonces, estuvo disponible en inglés para Shakespeare y compañía durante los tiempos en que estaba escribiendo para el teatro londinense.

En 1570, Roger Ascham, el maestro de latín de la princesa Isa- bel (después, reina de Inglaterra), tradujo al inglés, el Tiestes de Séneca, tragedia de la casa de Atreo (cf. Agamenón en la orestiada). Así fue cómo Séneca se conoció cerca de 1570 en Londres, en el ambiente de los dramaturgos y teatros de los tiempos de la Reina Isabel.

En 1579 fue publicada en inglés, en Londres, la elegante traducción de Sir Thomas North de Las vidas paralelas de los ilustres griegos y romanos de Plutarco que incluyó la vida de Pericles, que, a su vez, abarca todo lo relacionado con la Guerra del Peloponeso. El "Plutarco de North" fue disponible y conocido desde 1579 en Londres.

En 1611, George Chapman, erudito isabelino, tradujo y publicó las obras completas de Homero (Iliada, Odiseo, himnos homéricos) al bello y elegante inglés del período, conocido como Chapman's Homer.

Las historias griegas, entonces, eran más que conocidos; sus ideas fueron incorporados en las tragedias e influenciaron las tragedias isabelinas y jacobinas. Su provenance concuerda con las fechas y su disponibilidad para compra en Inglés de los "stationers" y libreros londinenses porque fueron todos publicados entre 1566 y 1611.

Tan temprano como en 1503, había traducciones de Sófocles y Euripides, al igual que las de 
Aristófanes, Terencio y Plauto eran asequibles en Europa como resultado de las traducciones al inglés y otras lenguas vernáculas por los humanistas cívicos de Europa. Su influencia sobre los dramaturgos comienza en el siglo XVIII con Jean Racine y Pierre Corneille en el continente, y continúa hasta hoy.

En fin, Grecia, sus dramaturgos y su historia fueron conocidos en traducciones al inglés, publicados en Londres, leídos y utilizados en las obras dramáticas del Londres isabelino y jacobino.

Que los primeros teatros isabelinos tenían que operar fuera de los límites municipales del poder del Lord Mayor de Londres, y funcionar en zonas de prostíbulos y arenas de peleas de gallos, perros y osos, nos dice que fueron excluidos de la vida legal londinense, porque existía el miedo de parte del poder del estado, incluyendo, principalmente, el trono, de que las obras dramáticas influyeran sobre las audiencias.

Eran tiempos de guerras de religión entre protestantes y católicos en el continente y guerras de baja intensidad de la misma índole en Inglaterra. La Reina Isabel temía no solamente la posibilidad que las guerras civiles-políticas-religiosas de alta intensidad, así como en Francia y entre España y los Países Bajos, podían infectar a su propio reino, pero, también, que habían fuerzas internacionales muy fuertes que querían derrocarla del trono, acusándola de herejía. Además temía la posibilidad de asesinato —que la podían quitarla su vida misma en los complots e intrigas en que la política fue entrelazada fuertemente con la religión.

En la paranoia de sus esfuerzas de autodefensa y defensa a su trono, Isabel transformó su reino en un estado policíaco con un enorme sistema de espías con poderes que incluía el interrogatorio bajo tortura, hasta asesinatos políticos. (Es muy posible, según evidencias $y$ argumentaciones que recientemente han sido publicadas ante la luz de investigaciones continuas, que Christopher Marlowe era un espía del trono inglés dirigido por Sir Francis Walsingham, jefe de los servicios de inteligencia y seguridad de Elizabeth. Según esta teoría, respaldada por alguna evidencia, se ha declarado que Marlowe llegó a penetrar el seminario jesuita de Douai en la costa norte de Francia de donde lanzaron misiones hacia la Inglaterra anglicana (léase protestante]. Se alega que Marlowe ingresó para recolectar información - y no solamente en los seminarios jesuitas de Douai- y que su muerte en una taberna en Londres en Deptford con una navaja clavada en el ojo fue un asesinato político Esta es el mismo período en que otras investigaciones filológicas ubican a William Shakespeare en Roma estudiando con los sacerdotes católicos, durante una temporada en que se 
dice que desapareció del escenario inglés).

Así que cuando se dio en 1601 la Rebelión de Essex en, y la compañía de actores de Shakespeare presentó, simultáneamente, una producción de Ricardo II, rey histórico de Inglaterra que enfrentó la rebelión más fuerte en la historia (1381), las comentarios de la Reina, al revisar las capturas y ejecuciones de los rebeldes indican que ella vio la conexión entre la rebelión y la producción teatral de Ricardo II. "Know ye nat that I am Richard II," dijo, [" ¿No saben que yo soy Ricardo II?"] dando claramente a conocer, en este bien famoso y reconocido pronunciamiento que entendió la relación entre la obra presentada y la rebelión recientemente aplacada con capturas y ejecuciones por traición. Eran tiempos peligrosos para la relación entre el teatro y el estado.

El muy reconocido cortesano protestante de la corte de Isabel, Sir Philip Sydney (poeta, teórico estético y mucho más), comenta, en su famosa Defense of Poesie (publicado en Londres en 1581) sobre el teatro isabelino como institución: "La tragedia alta y excelente que abre las heridas mas grandes y demuestra las úlceras que están cubiertas con telas finas, que hace que los reyes teman ser tiranos, y que los efectos de admiración y conmiseración enseñen la incertidumbre de este mundo. $Y$ muestra cuán débiles son los cimientos sobre las cuales los techos de oro están construidos."

["...the high and excellent tragedy that openeth the greatest wounds and showeth forthe the ulcers that are covered with tissue, that maketh kings fear to be tyrants, that with the stirring effects of admiration and commiseration, teaches the uncertainty of this world. And shows upon how weak foundations gilded roofs are builded."]

Ahora bien, Sydney era protestante (anglicano, de la Iglesia estatal de Inglaterra), pero no era puritano. Estos últimos odiaban el vestuario bello y ceremonial del teatro que los puso en mente de las liturgias de la Iglesia Católica. En 1642, con la Ilegada de Cromwell y la Guerra Civil en Inglaterra, el estado cerró definitivamente a los teatros y, así, efectivamente asesinó al teatro por ser subversivo al estado puritano. El teatro inglés no murió de causas naturales. Los católicos no objetaron, pero el estado se polarizó en la guerra política-religiosa entre los puritanos de Cromwell y los católicos de Carlos I.

Pero los asuntos no eran ni blancos ni negros. Sir Philip Sydney y su compatriota, el dramaturgo Thomas Heywood, también protestante, defendió el teatro contra el ala conservadora de los puritanos, antes de la Guerra Civil inglesa. Para ellos, el teatro sirvió una 
función para mantener el estado purgado y limpio de infecciones insurreccionales:

"[El teatro tiene el poder] de remodelar el corazón del espectador."

"[The theatre has the power] to new-mold the heart of the spectator." Thomas Heywood. An Apology for Actors (1512). B4r

Estas declaraciones y otras similares, que nadaban en aguas aristotélicas, corresponden a una visión de que, por medio de la piedad y el miedo, el ciudadano podía ser educado en su papel de ciudadano y sus límites. ¿Pero qué tal si hubiera dos estados en formación, enfrentados en la Guerra Civil —uno católico y el otro protestante? Se puede vislumbrar sombras, aquí, de la Atenas de Pericles en lo que era, en realidad, una guerra civil en la Guerra del Peloponeso (ambas partes en conflicto eran griegas).

Pero el colmo del control y censura del teatro - que Isabel y Jacobo, no obstante, amaban mucho- eran las funciones de un oficial importante en los gobiernos Tudor y Estuardo: The Master of the Revels [Contraloría de Espectáculos]. Una figura poderosa, tenía el poder, como funcionario gubernamental del trono, de cerrar los teatros completamente además de censurar, bajo reglamentos amplios, el contenido de las obras. Los dramaturgos tenían que presentar sus obras al Master of the Revels para revisión y censura (eliminación de palabras o escenas) antes de su producción.

Entre voluminosos reglamentos, por ejemplo, no se podía mencionar el nombre de Dios en el escenario a causa de las pasiones político-religiosas que hervían bajo la superficie, durante este período anterior a la guerra. [Un ejemplo solamente, entre muchos. El Master of the Revels proclamó, en nombre del gobierno y el trono, que no se podía jurar por el cuerpo de Jesús en el escenario-un juramento muy común de la calle, pero con implicaciones religioso-políticas: es decir, no se podía decir, "God's Body". Los dramaturgos y actores simplemente juraron por "Dog's body". Había control, pero no era absoluto en algunos casos].

El argumento concluyente de que, en este estado de espías tipo Stasi y los empujes negativos de los puritanos, además de los poderes $y$ funciones del Master of the Revels, junto con los poderes del Lord Mayor of London y Sir Francis Walsingham, espía maestro que respondió directamente a la Reina, había un fabuloso apoyo al teatro por parte del estado y trono. Las ambigüedades en la antesala de la Guerra Civil en la década de los 1640 alimentaron una suerte de esquizofrenia política y religiosa. Tenemos los ejemplos más famosos de los recusantes católicos cerca del 
trono de Isabel: William Shakespeare y Sir William Byrd, el compositor con una fama que reluce todavía hoy. El teatro no estaba inmune a lo anterior, y representó, con fidelidad, estas esquizofrenias: léase Hamlet estudiando en Wittenberg, entrevistándose con su padre muerto, recién venido del Purgatorio.

The Lord Chamberlain's Men (mas tarde, The King's Men), la compañía de actores teatrales, productores y dramaturgos (joint stock companies) a que pertenecía Shakespeare, fue patrocinada por el Rey Jacobo mismo y presentó actividades dramáticas con la protección del Rey Jacobo (I de Inglaterra y VI de Escocia), dentro de todos los demás formaciones gubernamentales para apoyar la integración de los ciudadanos en el estado en una manera ortodoxo-en la medida posible.

El teatro, una institución estética y comercial, existió y contribuyó al contexto de la dialéctica entre el estado y el crecimiento de Londres por medio del comercio marítimo de larga distancia, hasta que era el emporio imperante de Europa Occidental en el siglo XVI. Complicado por las tendencias insurreccionales de naturaleza política y religiosa, la justicia, en este ámbito, era siempre un asunto imperante en el Londres del siglo XVI. El nivel de homicidios bien podía haber Ilegado a un promedio de 12 al día, mientras el comercio marítimo creció a galope y los mercaderes ricos y poderosos maniobraron con mucha fricción dentro y fuera del estado. Este Londres, que aparece en los escenarios de Shoreditch y Londres, era el centro mercantil de Europa Occidental.

Las tierras que los campesinos ingleses habían sembrado por siglos fueron encerrados (mediante the enclosure $A c t$ ) para que solamente las ovejas de los ricos exportadores de lana, pudieran aprovechar de ellos. Desterrados así, vastos ejércitos de pobres hambrientos de las áreas rurales buscaban Londres para buscar su suerte alimenticia. La situación urbana que combinaba el hacinamiento, hambre porque la situación se estaba volviendo ingobernable, mientras que el desempleo y las tensiones religiosas crecieron. Había, por lo tanto, el problema de delincuencia social y escasez de justicia: véase el primer escenario en el mercado de Romeo y Julieta, cuando los pandilleros de los Montescos y los Capuletos inician la obra con una pelea sectaria que continúa por toda la tragedia y trae consigo múltiples asesinatos y suicidios. Esta situación desemboca en el final de la obra cuando el jefe de estado toma una posición "shakesperiana" sobre la violencia sectaria: "Una plaga sobre ambas casas," declara.

De esta situación social surgió el género de la tragedia de venganza que respondió a la falta de funcionamiento de las instituciones 
del gobierno y en que no se podía procurar a la justicia y la venganza individual de sangre era la única suposición para ganar la justicia. En este contexto, un tal Thomas Kyd presenta su obra, The Spanish Tragedy, en el escenario en Shoreditch, suburbio fuera de los límites municipales legales de la Ciudad de Londres en 1587.

La tragedia de Thomas Kyd presenta a individuos que buscan la justicia por sus propias manos porque las instituciones del gobierno no funcionan. El héroe, Hierónimo, a quien le asesina su hijo, Ilega a la locura por su tristeza y confecciona una obra dramática para presentarla ante el Rey de España. Los estados de España y Portugal están en guerra en esta obra que refleja la realidad histórica, y el matrimonio forzoso de Bel-Imperia al príncipe de Portugal

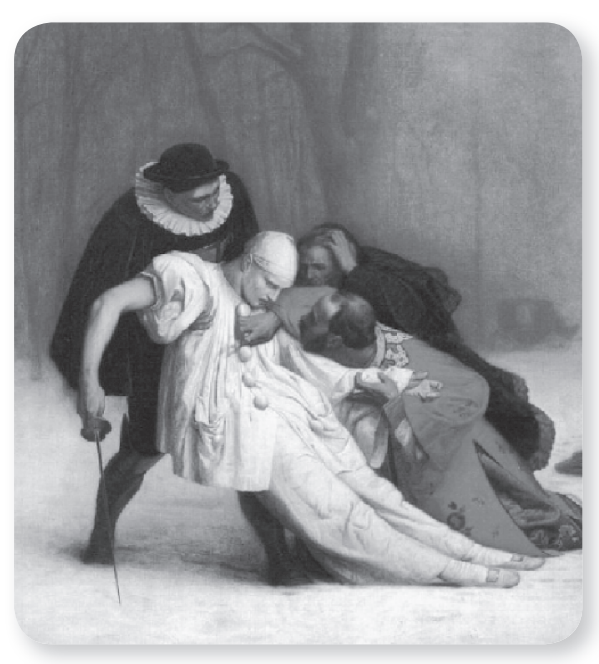

serían los que pone fin a la guerra con una alianza.

Pero como Bel-Imperia, la joven pieza de ajedrez en el juego de estados, amaba un joven español, Andrea, hijo de Hierónimo, y el hijo fue asesinado por conspiraciones portuguesas para que la alianza matrimonial siguiera entre España y Portugal por el matrimonio, Hierónimo no tiene donde buscar la justicia por su hijo asesinado en el entramado político entre los estados. En las estructuras ubicadas arriba, físicamente, del escenario en el teatro, durante toda la obra, es comentada por el "coro" [griego] del Fantasma de Andrea (ya muerto antes de que comience la tragedia) y la personificación de Venganza, un personaje en la tragedia.

En la obra teatral-el "play within a play" - Hierónimo presenta su caso, así como en Hamlet, pero los asesinatos en la obra son reales y el escenario termina cargado con cadáveres. Hierónimo busca el teatro para la justicia denegada por las instituciones del estado. Hay, entonces, una confluencia entre el teatro, la venganza y los asuntos políticos de alianzas entre estados.

Y esta no es la única obra dramática que señala que las instituciones del estado que tiene que ver con justicia no están funcionando. El teatro, por lo tanto, en Kyd, Shakespeare, Marlowe, Webster y 
demás, sufre, en toda su belleza y terror, una conscripción y es moldeado para servir fines políticos urgentes: el teatro es donde este dilema es actuado, y no es sencillamente una válvula de escape. Los cadáveres son reales, productos de la venganza individual porque el sistema de justicia está debilitado. Estos dramaturgos presentan una sociedad polarizada y en medio de olas fuertes de delincuencia y homicidio, en que el teatro sufre una metamorfosis y vuelve político por la inhabilitación del sistema de justicia del estado mismo.

Los dramaturgos isabelinos y jacobinos castigan al estado por esta falta, esta debilidad, esta ausencia de justicia e instituciones para velar por la justicia, obra tras obra. A la misma vez, presentan al final de las obras, o bien, una reafirmación de la validez del estado en sí, o bien, lamentan metafóricamente la ausencia de un estado viable.

Aquí es de tomar nota, entonces, que, Shakespeare, en sus obras teatrales siempre es el gran conservador, encerrando los egoísmos, fantasías, horrores, crímenes y desviaciones personales, sociales y políticas con una afirmación de la importancia de la monarquía-cumestado. The Revenger's Tragedy, The Roaring Girl, The Shoemaker's Holiday, The Atheist's Tragedy, el Jew of Malta, Hamlet, Macbeth, King Lear, Othello, Edward II, The Duchess of Malfi, 'Tis a Pity she's a Whore y todas las demás tragedias de venganza presentadas durante los reinados de Isabel I y Jacobo I antes de la Guerra Civil en Inglaterra que comenzó en 1642, presentan transformaciones estéticas de los mismos temas de la Orestiada: La justicia y el orden de una sociedad que son imprescindibles para el ser humano, su estado y su nación, eternamente en formación.

Por eso, las tragedias de venganza desde Esquilo hasta William Shakespeare y compañía llegan a ser un género literario que comenta los asuntos del estado en el escenario del teatro, pidiendo justicia. 